\title{
Linguagem, tecnologia e corporeidade: produção de significados para o tempo em gráficos cartesianos
}

\section{Language, technology and embodiment: Meaning production for time in Cartesian graphs}

\author{
Janete Bolite Frant ${ }^{1}$
}

\begin{abstract}
RESUMO
Este artigo discute a produção de significados para gráficos cartesianos por alunos do ensino médio. Em particular, trata do papel da tecnologia na emergência da compreensão dos alunos de gráficos de distância versus tempo, onde o tempo é um eixo componente do gráfico. Vinte e oito alunos do primeiro ano do ensino médio foram filmados enquanto resolviam uma atividade de esboçar um gráfico cartesiano para uma situação de movimento dividida em três momentos: 1- lendo uma estória e usando lápis e papel; 2 - trabalhando com calculadora gráfica e sensores de movimento; 3 - revisitando o gráfico esboçado em 1 . A teoria da cognição corporificada foi utilizada como fundamentação para analisar as produções de significado pelos estudantes sobre o produzido durante essa atividade. Os resultados mostram mudanças na percepção e na construção do eixo tempo, transformando o que antes era abstrato em algo palpável.

Palavras-chave: gráfico cartesiano; linguagem; produção de significado; tecnologia como prótese; teoria da cognição corporificada.
\end{abstract}

\footnotetext{
ABSTRACT

This article addresses and discusses meaning production for Cartesian graphs by high school students. In particular, it focuses on the role of tech-

1 Programa de Pós-Graduação em Educação Matemática / Universidade Bandeirantes de São Paulo (UNIBAN), Brasil; janetebf@gmail.com
} 
nology in the emergency of students' understanding of distance versus time graphs, in which time is an axis, a component of the graph. Twenty-eight junior high school students were videotaped while engaged in an activity of sketching a Cartesian graph for a movement situation in three steps; step one- reading a story and using pencil and paper; step two- working with a graphic calculator and a CBR sensor; step three- revisiting the graph done on step one. A theoretical framework based on embodiment theory was used for analyzing students' meaning production and how they change their thinking about time representation during the activity. The results pointed out to a change in perception and in building a time-axis, turning what was first an abstract entity to a palpable one.

Keywords: Cartesian graphs; language; meaning production; technology as prosthesis; embodiment theory.

\section{Introdução}

Interpretar e elaborar gráficos cartesianos são ações cruciais para alunos da segunda fase do ensino fundamental e do ensino médio tanto nas aulas de matemática como nas de ciências, física, química e biologia. Tal tópico acompanha os estudantes na universidade em diversas disciplinas, sem contar as diferentes informações que aparecem em jornais e revistas que utilizam gráficos cartesianos. Em geral, os alunos aprendem primeiro a posicionar um ponto no plano cartesiano. A maneira mais difundida é a de se aproveitar a arrumação da sala de aula, quase sempre uma carteira atrás da outra em filas, e associar cada "lugar" com uma determinada linha e coluna. Por exemplo, se Alex senta na terceira linha da segunda coluna podemos representar essa localização através do par ordenado $(3,2)$. Os estudantes costumam não ter dificuldades em resolver exercícios baseados nesta maneira de representar; no entanto, a dificuldade parece ser grande para representar no plano cartesiano $(\mathrm{x}, \mathrm{f}(\mathrm{x}))$. Minha visão é que embora as situações pareçam similares requerem mecanismos cognitivos distintos, por exemplo, na primeira situação não envolvemos variáveis.

Adoto a posição de Radford (2008, p. 1), que diz que: “Gráficos cartesianos são construtos semióticos... De fato, um gráfico cartesiano é um signo matemático complexo" . Ler um gráfico cartesiano pode parecer uma tarefa fácil, as informações parecem estar colocadas no mesmo. Entretanto, enxergar não implica necessariamente em ver (BOLITE FRANT; BARTO; DALLANASE; MOMETTl,

2 Grifo do autor, não no original. 
2004), temos que aprender como ver e entender este signo matemático.

Numa perspectiva da neurociência, Sacks (1995) afirma que não é necessária a conexão entre o mundo tátil e o mundo da visão; sobretudo, ele coloca que de acordo com Berkeley uma conexão entre eles pode ser estabelecida somente a partir da experiência.

Isso posto, é preciso entender melhor as dificuldades apresentadas pelos alunos para ler, interpretar e elaborar gráficos cartesianos e intervir no ensino modificando o cenário de aprendizagem de modo a discutir e superar tais dificuldades. Duas questões nortearam este estudo:

- Que significados para o eixo tempo em gráficos cartesianos são produzidos pelos alunos?

- Qual o papel da tecnologia na emergência da compreensão do eixo tempo nestes gráficos?

Ao lidar com linguagem acredito ser importante informar como usarei neste artigo linguagem, conhecimento, produção de significado, entre outras, porque essas palavras vêm sendo utilizadas com perspectivas diversas.

\section{Escolhas teóricas}

Na plenária do PME em 1998, Stephen Lerman ${ }^{3}$ levantou a necessidade de novas lentes para analisar as pesquisas em educação matemática que incluam e valorizem os diálogos, as interações, que ocorrem na sala de aula de matemática.

Desde então, para entender as interações que têm lugar em cenários de aprendizagem com tecnologia, venho baseando minhas análises nas ideias do filósofo russo Mikhail Bakhtin sobre linguagem em articulação com a teoria da cognição corporificada, principalmente no trabalho dos linguistas cognitivos George Lakoff, Gilles Fauconnier, Mark Johnson, Leonard Talmmy e do psicólogo Rafael Núñez. Deste modo estas vozes ecoam sobre meu trabalho mesmo que não tenham sido explicitamente referidas.

A linguagem é o material que escolhi para abordar analiticamente diálogos e interações. Meu ponto de partida é que a linguagem está enraizada em nossa experiência com o mundo que habitamos. Diferentemente dos dicionários que definem uma palavra em termos de outras, nós, seres humanos, entendemos

3 Presidente do PME - Psychology and Mathematics Education - de 1995 a 1998. 
(produzimos significados) uma palavra interagindo com outros seres humanos (pais, colegas etc.) e com o mundo. Por exemplo, como poderíamos explicar a uma criança usando apenas palavras o que é vermelho, pesado, entre outras? Assumo ainda que o que o senso comum chama de abstrato em matemática também se aprende do mesmo modo, isto é, interagindo com outros seres humanos e com o mundo ao redor.

Propomos duas metáforas para o conhecimento, a caixa e a faixa de Moebius. Se o conhecimento for pensado como uma caixa, podemos dizer tal aluno tem um conhecimento superficial, como se o conhecimento fosse algo que pode se encontrar mais na superfície, como a de uma caixa, enquanto outros conhecimentos pudessem se localizar nas partes mais profundas da mesma. Neste caso, o conhecimento pode ser transferido como transferimos uma caixa de um lado ao outro. Podemos ainda pensar num conhecimento "perdido" como algo que caiu da caixa, e assim por diante. Apesar de parecer caricaturais, tais expressões são utilizadas em nossa área. Afinal a caixa é um espaço que "experienciamos" e, portanto, conhecemos muito bem. Nascemos em um quarto, uma caixa, existem coisas dentro, fora da "porta"; enfim, o "novo conhecimento" estaria fora do quarto, esperando para entrar; as representações seriam externas ao indivíduo e o pensamento seria interno.

No entanto, se pensarmos o conhecimento como uma faixa de Moebius, uma nova concepção surge e termina o dilema interno/externo. De acordo com a artista plástica Lygia Clark (1983, p. 151): “[...] se eu utilizo uma fita de Möebius para esta experiência, é porque ela contrasta com nossos hábitos espaciais: direita-esquerda; avesso-direito etc. Ela nos faz viver a experiência de um tempo sem limite e de um espaço contínuo."

Assim, conhecer é uma ação realizada por um indivíduo num espaço necessariamente social, cultural e histórico. Afirmo ainda ser impossível e desvantajoso isolar um ser humano de seu ambiente social, cultural e histórico para investigar sua produção de conhecimento. Acrescento, considerando como um texto todo o "saber" escrito ou enunciado por outros. Um livro, um comentário de um colega, a fala do professor, coisas escritas no quadro são textos e continuam sendo textos até que um indivíduo interaja com o mesmo para então produzir significado para o mesmo. Este processo de interação é um processo que envolve representações multimodais. Barsalou (2008), no exemplo abaixo, mostra como aprendemos o que é uma cadeira.

Quando uma experiência ocorre (p.e. sentar gostosamente reclinado numa cadeira), o cérebro captura estas situações através de diferentes modalidades e as integra guardando uma representação multimodal em 
nossa memória (p. e., como a cadeira é fisicamente e sua sensação, a ação de sentar, introspecções de seu conforto e relaxamento). Mais tarde, quando é necessário um conhecimento para representar uma categoria (cadeira) as representações multimodais capturadas durante as experiências são reativadas para simular como o cérebro representou esta percepção, ação e introspecção associadas a este conhecimento (BARSALOU, 2008, p. 1).

De acordo com Lins (1997), a produção de significado para um objeto é tudo o que é dito sobre o mesmo e não o que poderia ser dito. Assumimos ainda que nossa fala inclua uma variedade de modos de expressão tais como expressão facial, gestos, mudanças no tom de voz, entre outros. E que os objetos são constituídos na e pela fala segundo a perspectiva bakhtiniana.

O diálogo a seguir pode ser rapidamente compreendido, sem esforço. João se dirige a Bernardo e diz: "Tudo bem contigo?"; Bernardo (levanta o polegar). Podemos afirmar que Bernardo está bem. Como entendemos que Bernardo está bem e não que ele está indo a algum lugar no andar de cima?

Lakoff e Johnson $(1980 ; 1999)$ afirmam que nosso sistema conceitual - o modo pelo que pensamos e agimos - é fundamentalmente metafórico. A perspectiva corporificada da linguagem nos traz que as metáforas não são meramente figuras de linguagem, mas estão intrinsecamente relacionadas ao pensamento. Também não separo linguagem e pensamento do mesmo modo que não separo mente e corpo; sigo os passos de Damasio (1994) e Lakoff e Johnson (1999).

Realizar qualquer atividade cotidiana é tão complexo que ultrapassa descrições formais. Por exemplo, pense em ir à escola e assistir seis aulas distintas. Isto envolve caminhar ou tomar uma condução até a escola, selecionar qual a sala em que se deve entrar, escolher um lugar para sentar, pegar caderno e caneta para anotar, e assim por diante. Tais rotinas, que nos parecem tão naturais, necessitam a coordenação de muitas ações tais como movimentar, perceber, sentar, pensar e agir num mundo tridimensional. Os linguistas cognitivos continuam não entendendo, ao certo, o número exato e a natureza desses padrões, mas oferecem uma noção que pode nos auxiliar a entender esses fenômenos rotineiros, a ideia de esquema-imagem.

Cabe observar que esquema-imagem é uma noção composta e como tal não é nem esquema, nem imagem no sentido tradicionalmente atribuído. Como uma noção composta, traz uma nova possibilidade nesta composição que não pode ser encontrada em cada palavra isoladamente. Por exemplo, se quisermos explicar por que a água apaga o fogo não encontramos explicação via o oxigênio nem via o hidrogênio. De acordo com Johnson (1987), um esquema-imagem é uma (re) descrição de uma experiência perceptiva visando mapear estruturas 
específicas em estruturas conceituais.

Um mapeamento conceitual é um mecanismo que permite organizar e reorganizar o pensamento. Nosso ponto de vista é que o pensamento e sua organização ocorrem na maior parte das vezes de modo inconsciente, não no sentido freudiano, mas de modo que podemos não estar conscientes de como tal processo se desdobra. Um tipo de mapeamento importante é a metáfora conceitual, que é um mapeamento intradomínios que preserva inferências do domínio fonte nas inferências sobre o domínio alvo. Em outras palavras, trata-se de um mapeamento inconsciente entre um domínio fonte, bem conhecido, em um domínio menos familiar que, ao levar as inferências estruturais do domínio fonte, permite-nos uma compreensão do domínio alvo a ser construído. É importante dizer que nem todo mapeamento conceitual deriva da experiência física, apenas os conceitos mais básicos de matemática o são. Proponho que os esquemas-imagem têm um papel crucial nestes mapeamentos evitando a experiência física direta como um único elemento para o mapeamento estrutural. Por exemplo, alunos de cálculo trabalhavam com uma simulação para derivada de função real de uma variável, como mostra a Figura 1 (STEWART, 2009).

\section{Using the Secant to Find the Slope of the Tangent}

The slope of the tangent line to a curve at $P$ depends only on the shape of the curve near $P$.

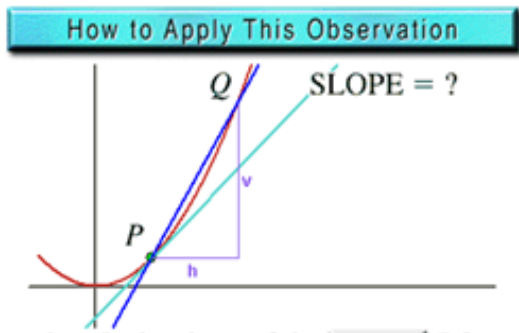

As $Q$ approaches $P$, the slope of the $\mid$ secant $P Q$ approaches the slope of the tangent at $P$.

\section{j以ily 彭}

FIGURA 1 - SIMULAÇÃO PARA DERIVADA DE FUNÇÃO REAL DE UMA VARIÁVEL

4 Figura retirada do CD que acompanha o livro de Stewart (2009). 
Os estudantes concordavam que o ponto Q "se transformava" no ponto P. E através da análise dos diálogos a metáfora encontrada foi: PONTOS SÃO COISAS FÍSICAS, conforme Quadro 1 abaixo.

\begin{tabular}{|l|l|}
\hline DOMÍNIO FONTE & DOMÍNIO ALVO \\
\hline Um corpo no espaço & Um ponto no plano cartesiano \\
\hline Um carro se movendo numa trajetória & $\begin{array}{l}\text { Um ponto se movendo numa curva que } \\
\text { representa uma função }\end{array}$ \\
\hline $\begin{array}{l}\text { Um carro que entra num túnel é o mesmo } \\
\text { carro quando sai do túnel }\end{array}$ & $\begin{array}{l}\text { Um ponto que se move ao longo do gráfico } \\
\text { é o mesmo em qualquer posição }\end{array}$ \\
\hline $\begin{array}{l}\text { A trajetória representa o movimento do } \\
\text { carro }\end{array}$ & $\begin{array}{l}\text { O gráfico na tela representa a trajetória do } \\
\text { movimento }\end{array}$ \\
\hline
\end{tabular}

QUADRO 1 - METÁFORA: PONTOS SÃO COISAS FÍSICAS

Os gestos dos alunos eram bastante icônicos e sugeriam que o ponto $(\mathrm{x}, \mathrm{y})$ e o ponto $(a, b)$ podiam ser o mesmo, ainda que $\mathrm{x}$ fosse distinto de $\mathrm{a}$; ou seja, a posição do ponto no plano cartesiano não importava. (para maiores detalhes, ver Bolite Frant et al., 2004). O esquema-imagem para "corpo que se move no espaço" ajudou esses alunos a fazer as inferências acima. Podemos dizer que tal esquema-imagem compôs o domínio fonte desses alunos.

Como tecnologia, proponho uma nova metáfora, a da prótese. Se usar as ideias de Descartes para pensar o ser humano, posso compará-lo a uma máquina, em particular, a um computador. E assim posso pensar a cognição humana usando palavras como interface, nós, aprendizado como rede, e assim por diante. Mas, se penso o ser humano como humano, parece óbvio, mas não é, empregar outras palavras como emoção, tomada de decisão, prótese entre outras. Para mim, a prótese vai além de reparar alguma falta. Por exemplo, é difícil dizer exatamente onde termina o tato para um cego: na sua mão ou na bengala? Neste caso fica mais claro entender que a bengala não é apenas um objeto auxiliar da visão, mas um artefato que modifica a percepção de quem o usa. Sobretudo a prótese oferece um novo texto provocando uma nova produção de significado.

Retomando a visão do gráfico cartesiano como um construto semiótico, no estudo relatado a seguir, nosso interesse foi pelos símbolos usados pelos estudantes para registrar variações no tempo e como eles modificaram seu modo de produzir significado para o eixo do tempo quando utilizaram a calculadora gráfica e o sensor. 


\section{A investigação em campo}

Alice $^{5}$, a professora de matemática, havia participado de um grupo de estudos onde teve contato com o kit-calculadora gráfica e sensor de movimento - e com a atividade do Joãozinho, um menino meio desligado que vivia na mesma rua da escola que ficava umas dez quadras da sua casa. Trabalharam nos três momentos, 1 - ouvindo a estória e esboçando o gráfico que representava a estória; 2- justapondo um gráfico na tela da calculadora movimentando o corpo; e 3 - revendo o gráfico esboçado.

No grupo de estudos, as professoras comentaram o quão importante foi usar o kit para a compreensão de gráficos do tipo dxt. Três meses depois, Alice voluntariamente pediu emprestados os kits e a filmadora para usar em sua sala de aula. Eram vinte e oito alunos do primeiro ano do Ensino Médio (EM) de uma escola pública em Minas Gerais, que estudavam funções na aula de matemática, com Alice, e cinemáticas, na aula de física. A professora de física abriu mão de uma aula e assim Alice teve dois tempos geminados para trabalhar. Três professoras do grupo de estudos foram com ela até a escola. Arrumaram a sala de modo a deixar os alunos trabalhando em grupos de 4, deixando um espaço livre para a movimentação com o kit e um espaço na frente do quadro.

Com o cenário pronto, os estudantes chegaram e espontaneamente se distribuíram nos pequenos grupos. As demais professoras ficaram próximas aos grupos para fazerem anotações e se preocuparam em ajudar de forma não invasiva.

Alice distribuiu, inicialmente, a folha de atividade com a estória do Joãozinho para que eles esboçassem o gráfico que a representava. Depois cada grupo escolheu um representante que foi ao quadro esboçar, justificando, o gráfico que haviam feito. Cinco gráficos diferentes foram colocados no quadro e os seis grupos não conseguiram neste momento decidir qual era o que melhor representava o movimento do Joãozinho.

No segundo momento, Alice e as demais professoras distribuíram os kits. A tarefa agora era justapor o gráfico que randomicamente era gerado na tela da calculadora. E depois dessa etapa eles voltariam aos seus esboços.

Destacaremos nesta atividade com lápis e papel o episódio $\mathbf{O}$ tempo pode andar para trás.

A seguir destacamos a tarefa do primeiro momento:

5 Alice é, naturalmente, um nome fictício para a professora da turma. Também são fictícios os nomes dos estudantes que aparecem na sequência. 
Tarefa 1 - Esboce um gráfico cartesiano que represente os movimentos de Joãozinho na estória a seguir:

Joãozinho é um menino bem distraído. Segunda-feira então... É um problema.

Era uma segunda e Joãozinho que mora na mesma rua da escola, dez blocos de distância apenas, foi para a escola. De repente lembrou-se que esqueceu do dever de casa em cima de sua cama. Voltou em casa, pegou o dever e foi de novo para a escola. Já estava quase chegando quando lembrou que havia esquecido o livro que deveria levar para a aula de inglês. Mais uma vez voltou em casa e saiu correndo para a escola de modo a chegar na hora certa.

Os alunos começaram a pensar no gráfico, trabalhando em pequenos grupos de 4 ou 5 participantes. Um problema era desenhar a "volta" do Joãozinho, como veremos nos trechos excertos dos diálogos entre os alunos.

Luiza havia desenhado um "laço" para representar a ação de voltar, o eixo vertical representava a distância/posição e o eixo horizontal o tempo. E Maria também interagia.

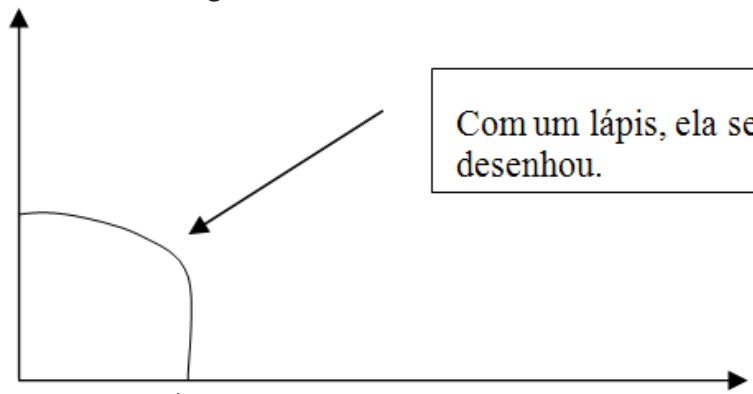

FIGURA 1 - GRÁFICO DE LUZIA

Maria: "Como ele voltou aqui?".

Luzia: "Porque é um gráfico.".

[Maria argumenta que no eixo horizontal está o tempo.].

Luzia: "Tá certo! Mas... Eu estou acostumada a colocar o T aqui."

(indicando o eixo vertical).

Beatriz retrucou, dizendo que "se fosse assim não seria gráfico".

Aqui, podemos interpretar que um gráfico é também um gênero de discurso segundo Bakhtin $(1995 ; 2003)$. Isto é, existe um modo particular para "falar" (desenhar) gráfico de função e Beatriz apontava para tal.

Cabe observar que em nenhum livro didático o gráfico dxt é representado com o tempo no eixo vertical. No entanto, em todos os livros de matemática, quando falamos no gráfico XxY e em uma função $f(x)$, o par que representa um 
ponto que pertence à função é $(\mathrm{x}, \mathrm{y})$ que representa a abscissa x e a ordenada y. Já nos gráficos de cinemática dxt e uma função $f(\mathrm{t})$, o par que representa um ponto que pertence à função é da forma $(\mathrm{t}, \mathrm{d})$. Ou seja, existe uma inversão para que os gráficos representem uma função, mas que não é sequer comentada. Assim, quando a aluna se referiu ao eixo $\mathrm{T}$ na vertical, ela poderia estar se referindo ao fato de que "coisas" do tipo dxt deveriam trazer d na horizontal e t na vertical.

Ao mesmo tempo, nossa hipótese é a de que as alunas estavam pensando no problema visualizando apenas uma dimensão - o rastro de Joãozinho no chão - e não estavam confortáveis para representar o movimento de retorno à casa do Joãozinho.

Um outro grupo também encontrava dificuldades em representar os movimentos de retorno no gráfico e decidiram usar linha cheia quando Joãozinho ia em direção da escola e linha pontilhada quando ele retornava à casa. Esse grupo chamava Alice com frequência para que ela dissesse se estava certo ou não o que estavam fazendo.

Alice, olhando o gráfico abaixo reproduzido (Figura 2), sem entender, pediu que os alunos o explicassem.

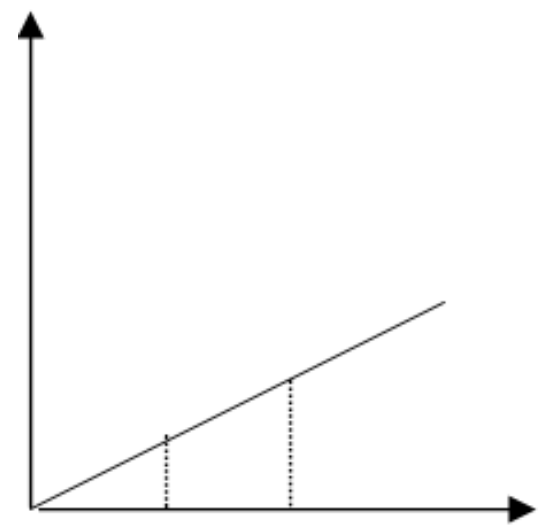

FIGURA 2 - ESBOÇO DO GRÁFICO DO GRUPO 3

Abaixo segue o diálogo entre Alice e os alunos do grupo 3.

A1G3: "Ele andou 2 minutos... ele tá aqui... (apontando para o eixo vertical no ponto 2) Aí ele voltou, é negativo...menos 2.".

Alice: "Ele andou até aqui, não foi?"” (apontando ao primeiro ponto no gráfico). A1G3: "Nãão! Até aqui.".

Alice: "Aí esqueceu algo e voltou, onde está a volta?".

A1G3: "Ele voltou... pra baixo." (apontando para a linha pontilhada que ia até o eixo horizontal). 
A figura abaixo mostra o gesto de A3G3 que coincide com o esboço do gráfico na Figura 2.

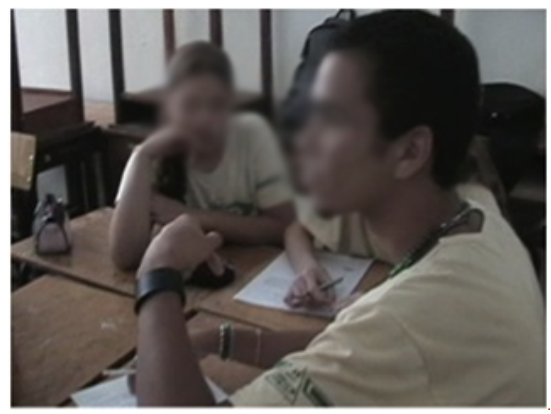

A3G3: "Ele voltou. "negativo" "...menos 2.". E a discussão continuava:

A3G3: "Ah não, quando ele está voltando é negativo." A4G3: "Se o tempo está correndo não significa que é menos não." A2G3: "Lógico que é menos, de dois se tira dois... Ele andou dois e voltou dois. Ele voltou pro zero."

O que estava acontecendo? Será que Joãozinho parou o tempo? O restante do grupo não interagia com A4G3, pareciam concordar com A3G3.

Observe-se que as inferências realizadas levaram em conta a adição e subtração de números inteiros que foram mapeados no novo domínio tempo. Por isso se Joãozinho andou 2 minutos e voltou 2, o tempo é zero. A metáfora TEMPO É NÚMERO NA RETA emergia, conforme o Quadro 3. 


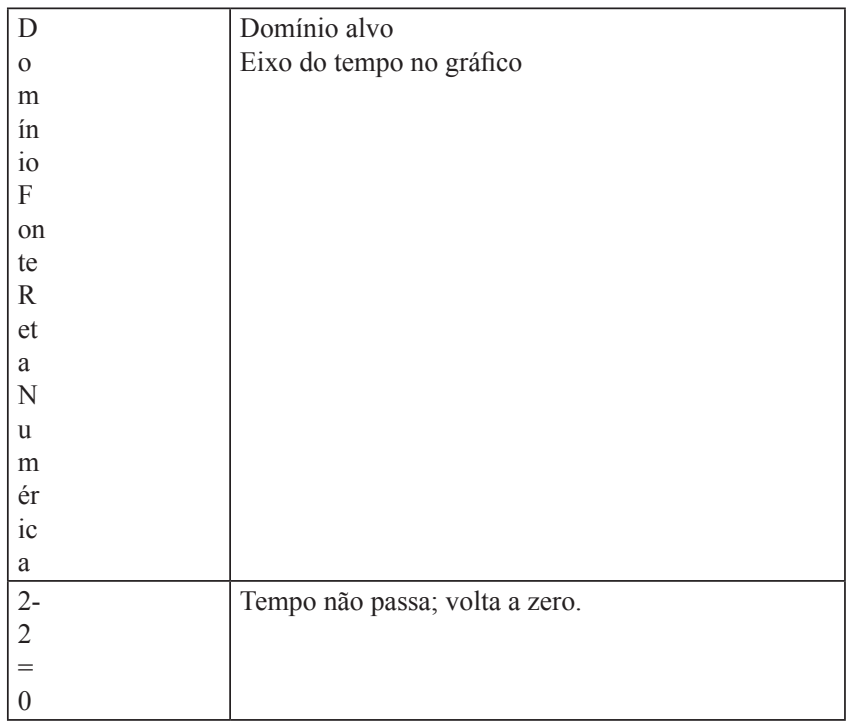

QUADRO 3 - METÁFORA TEMPO É NÚMERO NA RETA

Um outro episódio surge ao usarem o kit como prótese: O tempo sempre anda e outras.

Os estudantes estavam entusiasmados com o kit e, enquanto a professora explicava a nova tarefa, A4G3 apertou a tecla ENTER da calculadora. Um gráfico começava a ser traçado na tela, uma reta paralela ao eixo horizontal. E essa aluna, que havia tentado em vão convencer os colegas do grupo que o tempo sempre andava, ganhava agora um novo argumento, o gráfico desenhado quando ela estava em pé parada. Então A4G3, aos berros gritava: "Eu sabia....o tempo sempre corre, não volta pro zero não... hahahaha...".

Os colegas olharam para a tela e imediatamente se convenceram desse fato. A atitude dos alunos agora era bem distinta, suas faces que na atividade com o lápis e papel estavam contraídas se suavizavam com o kit, e quando um gráfico não justapunha ao da tela ouviam-se risadas e imediatamente recomeçavam a tarefa, não chamavam mais Alice já que tinham um feedback imediato na tela.

Cada movimento que faziam tinha uma representação bidimensional. Essa prótese começava a ajudá-los a compreender a variável tempo no gráfico. O que parecia impossível, se tornava palpável ou objetificado segundo Luis Radford ${ }^{6}$.

6 Luis Radford trata de objetificação em vários artigos que podem ser encontrados em $<$ http://www.laurentian.ca/Laurentian/Home/Departments/School+of+Education+French/ Faculty+and+Staff/Luis+Radford/Publications/publications.htm?Laurentian_Lang=en-CA $>$. 

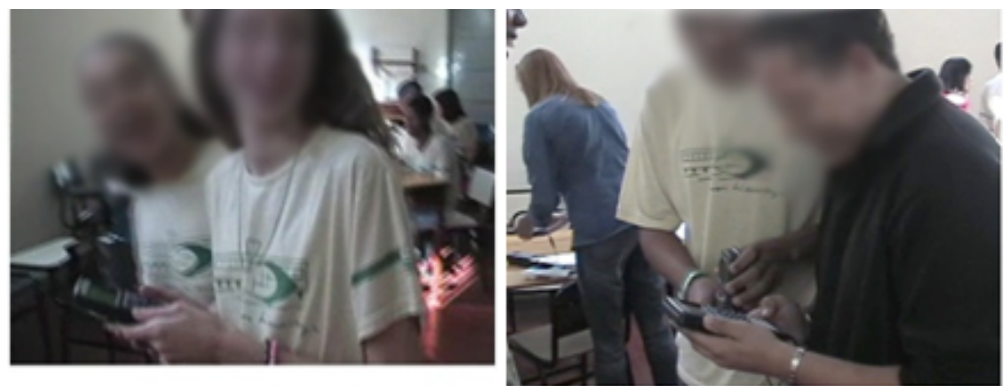

De acordo com a teoria da cognição corporificada, podemos afirmar que com esta prótese, em cada pequeno grupo, os alunos ampliavam seus domíniosfonte, pois um gráfico cartesiano do tipo dxt era construído na tela da calculadora enquanto o sensor capturava seus movimentos em duas dimensões. Quando todos os grupos terminaram esta tarefa, Alice os convidou a revisitar seus gráficos do Joãozinho. Tarefa que foi realizada com mais tranquilidade e compreensão por parte dos alunos.

\section{Diferentes perspectivas para o TEMPO emergiram neste processo}

\section{O tempo pode voltar, ser negativo e até parar...}

A reta numérica e os rastros são possíveis domínios-fonte e todos apresentam uma perspectiva unidimensional.

\section{O tempo sempre anda!}

O sensor e a tela da calculadora são possíveis domínios-fonte, agora uma perspectiva bidimensinal.

\section{Compreendendo o eixo do tempo nos gráficos dxt.}

Trata-se de um esquema-imagem enriquecido pelo uso da prótese; agora, $\mathrm{o}$ domínio-fonte contava entre outros com a reta numérica, com os rastros, o sensor capturando movimento, e a tela da calculadora gráfica (ora unidimensional ora bidimensional) permitindo a coordenação dos eixos envolvidos. 


\section{Considerações Finais}

Experiências corpóreas de crescer, movimentar-se para os lados, andar de skate, deslizar ladeira abaixo, deixar marcas dos pés na areia, entre outras, ajudam a estruturar nossas ideias e inferências sobre a representação gráfica de funções; mas, de modo geral, são experiências unidimensionais. Para o grupo de alunos estudado, seus esquemas-imagem e, consequentemente, seus domínios alvo foram enriquecidos com o uso da prótese (tecnologia) que permitiu pensar de modo bidimensional.

É importante ressaltar que atividades onde os estudantes possam se movimentar ao longo de uma reta, usando cronômetro, também são importantes, mas não tornam o eixo do tempo palpável. O eixo do tempo continua "invisível" e a trajetória é mais enfatizada.

Observemos que as tarefas realizadas para atender as questões desta pesquisa não tinham a intenção de verificar se os alunos iriam melhor em cenários utilizando lápis e papel ou tecnologia. $\mathrm{Na}$ tarefa 1, eles recebiam uma estória; na tarefa 2, tinham que justapor um gráfico, assim, cada tarefa os desafiava de modo diferente e complementar. Na tarefa 1, a partir da estória deveriam elaborar um gráfico e, na tarefa 2, a partir de um gráfico dado deveriam reproduzi-lo.

Os alunos se sentiram confortáveis com o kit. Para eles era como um jogo, mas cada movimento tinha sua representação bidimensional. Assim, eles, os alunos, enriqueciam seu repertório.

Podemos afirmar que a teoria da cognição corporificada abriu uma nova janela para a compreensão da produção de significado pelos alunos, para nós, pesquisadores e professores envolvidos nesse tipo de investigação. A tecnologia trouxe a possibilidade de resolver o problema proposto e foi além: tornou tangível o que era invisível e ofereceu um contexto bidimensional, permitindo a coordenação dos eixos no gráfico cartesiano.

\section{REFERÊNCIAS}

BAKHTIN, M. Marxismo e Filosofia de Linguagem. 7. ed. São Paulo: Hucitec, 1995. . Estética da criação verbal. 4. ed. São Paulo: Martins Fontes, 2003.

BARSALOU, L. Grounded cognition. Annual Review of Psychology, v. 59, 2008. 
BOLITE FRANT, J.; BARTO, M. C.; DALLANASE, C.; MOMETT1, A. Reclaiming Visualization: When seeing doesn't imply looking. ICME10, Denmark, 2004. TSG 28 $<\mathrm{http}: / /$ www.icme10.dk/>.

CLARK, H. Speaking in Time. Speech Communication, v. 36, 2002.

CLARK, L. C. Livro-obra. Rio de Janeiro: [s.n.], 1983.

DAMASIO, A. Descartes’Error. Nova York: Avon Books, 1994.

JOHNSON, M. The body in the mind: the bodily basis of imagination, reason and meaning. Chicago: University of Chicago Press, 1987.

LAKOFF, G. The contemporary theory of metaphor. In: ORTONY, A. (Ed.). Metaphor and thought. 2 ed. Cambridge: Cambridge University Press, 1993. p. 202-251.

LAKOFF, G.; JOHNSON, M. Metaphors we live by. Chicago: University of Chicago Press, 1980.

. Philosophy on the Flesh. Nova York: Basic Books, 1999.

LERMAN, S. A moment in the zoom of a lens: towards a discursive psychology of mathematics teaching and learning. In: OLIVIER, A.; NEWSTEAD, K. Proceedings of the Twenty-second Annual Meeting of the International Group for the Psychology of Mathematics Education, Stellenbosh, South Africa, v. 1, p. 66-81, 1998.

LINS, R. O modelo teórico dos campos semânticos. UNESP, 1997. (Entrevista registrada em áudio).

NEMIROVSKY, R.; FERRARA, F. Mathematical imagination and embodied cognition. Educational Studies in Mathematics, v. 70, n. 2, 2008, p. 159-174.

NÚÑEZ, R. Mathematical idea analysis: What embodied cognitive science can say about the human nature of mathematics? In: NAKAHARA, M.; KOYAMA, M. (Eds.). Proceedings of the 24th International Conference for the Psychology of Mathematics Education, Hiroshima, Japan, v. 1, p. 3-22, 2000.

OAKLEY, T. Image-Schema. In: GEERAERTS, D.; CUYCKENS, H. (Eds.). Handbook of cognitive linguistics. Oxford, U.K.: Oxford University Press, 2006. Cap. 9.

RADFORD, L. Culture and cognition: Towards anthropology of mathematical thinking. In: ENGLISH, L. (Ed.). Handbook of International Research in Mathematics Education. 2 ed. Nova York: Routledge, Taylor \& Francis, 2008. p. 439-464.

RADFORD, L.; MIRANDA, I.; GUZMÁN, J. Relative motion, graphs and the heteroglossic transformation of meanings: A semiotic analysis. In: FIGUERAS, O.; 
CORTINA, J. L.; ALATORRE, S.; ROJANO, T.; SEPÚLVEDA, A. (Eds.). Proceedings of the Joint $32^{\text {nd }}$ Conference of the International Group for the Psychology of Mathematics Education and the 30th North American Chapter, v. 4, p. 161-168, 2008.

SACKS, O. Um antropólogo em Marte. Rio de Janeiro: Companhia das Letras, 1995.

STEWART, J. Cálculo I. 6. ed. São Paulo: Editora Thomson Pioneira, 2009. 